\title{
EDUCAÇÃO FÍSICA E DIVERSIDADE CULTURAL: UM DIÁLOGO POSSÍVEL
}

Rogério Cruz de Oliveira

\section{Resumo}

O objetivo deste artigo é discutir o ensino da educação física no que se refere às diferenças culturais apresentadas pelos educandos no cotidiano escolar. A diversidade cultural é um tema em destaque no cenário educacional brasileiro. $\mathrm{O}$ debate ocorre em torno de como articular processos educativos que considerem as diferenças dos alunos. Entendo essa premissa como um avanço, no entanto com riscos de um relativismo extremo. Assim, entendo residir na perspectiva intercultural de educação - a qual tem na alteridade o argumento relevante do diálogo entre as culturas - um caminho possível para o ensino da educação física.

\section{Palavras-Chave}

Educação Física; Cultura; Diversidade Cultural e Alteridade.

\section{PHYSICAL EDUCATION AND CULTURAL DIVERSITY: A POSSIBLE DIALOGUE}

Rogério Cruz de Oliveira

\begin{abstract}
The objective of this paper is to discuss the teaching of Physical Education concerning the cultural differences presented by the pupils in the school routine. The cultural diversity is an emphasised topic in the Brazilian educational setting. The debate takes place around how to articulate educational processes that might consider the differences between the students. I understand such a premise as an advance - at the risk, however, of reaching an extreme relativism. Thus, I understand that a possible way for the teaching of Physical Education dwells on the intercultural perspective of education - which has, in alterity, the relevant argument for the dialogue between the cultures.
\end{abstract}

\section{Key-Words}

Physical Education at school; Culture; Cultural diversity; Alterity 


\section{INTRODUÇÃO}

"Há diferenças e há igualdades, e nem tudo dever ser igual e nem tudo deve ser diferente".

Boaventura Santos (MALERBA, 1995)

O intenso debate acadêmico ocorrido na década de 1980 fez com que a Educação Física (EF) ampliasse a sua visão de área e, conseqüentemente, repensasse a sua ação pedagógica na escola, até então, moldada em pressupostos tecnicistas. Tais pressupostos advogavam para a EF a ênfase na repetição de exercícios físicos, de maneira que as técnicas, tratadas de forma instrumental, pudessem ser executadas corretamente pelos alunos e se aproximassem do gesto técnico dos esportes de competição. A justificativa dessa prática de EF pautava-se no argumento, advindo das ciências naturais, de que, sendo o corpo um conjunto biológico, responderia sempre da mesma forma, porque os homens possuem corpos semelhantes (DAOLIO, 2003). Ou seja, se todos possuem os mesmos órgãos, nos mesmos lugares e exercendo as mesmas funções, as práticas corporais a serem abordadas na escola, por meio da EF, devem ser iguais para todos, ao mesmo tempo e da mesma forma.

A partir da inserção das ciências humanas no debate acadêmico, advinda de autores da EF que buscaram na sociologia, filosofia, ciência política, antropologia, dentre outras ciências, seu referencial teórico de estudo, o paradigma tecnicista começou a ser questionado e criticado quanto aos seus argumentos e aplicações no âmbito escolar. Esse fato fez surgir, a partir do final da década de 1980, várias abordagens da EF que buscavam superar tal modelo.

Sem entrar, especificamente, no mérito de cada abordagem, pois não é objetivo deste estudo a caracterização de cada uma, entendo que o debate acadêmico, que se prolongou pela década de 1990 até os dias de hoje, acabou por realçar a questão sociocultural na EF. Ou seja, parece haver um "consenso", não negando as tensões que existem entre cada uma das abordagens, visto à diversidade dos referenciais teóricos, de que o ensino da EF deve levar em consideração a realidade sociocultural dos alunos.

Diante do exposto é que entendo a ação pedagógica da EF como eminentemente cultural. Parafraseando Daolio (2003), tal ação deve considerar, num sentido mais amplo, o contexto sociocultural onde ela se dá, e, num sentido mais específico, as diferenças existentes entre os alunos e os grupos de alunos.

Esses pressupostos, acima explicitados, não são exclusivos do debate acadêmico da $\mathrm{EF}$, mas estão presentes nas discussões da educação escolar como um todo. Na atualidade, visto a necessidade da escola superar processos educativos tradicionais e práticas excludentes, a premissa do "ensino a partir da 
realidade" do aluno há muito vem sido discutida e enfatizada nos cenários acadêmico e social, tendo sido destaque nos últimos anos. A Lei de Diretrizes e Bases da Educação Nacional (LDB 9394/96) discorre, em seu texto, sobre a incorporação, nos currículos de ensino fundamental e médio, de uma parte diversificada que contemple as características regionais e locais da sociedade, da cultura, da economia e da clientela. No texto dos Parâmetros Curriculares Nacionais (PCN's) - divulgado a partir de outubro de 1997, a temática da pluralidade cultural está incluída como tema transversal no terceiro e quarto ciclos escolares, versando sobre a necessidade da escola enfocar a diversidade cultural (BRASIL, 1997).

Assim, parece-me oportuno abordar neste estudo o ensino da EF diante da diversidade cultural dos educandos, entendendo como um avanço a consideração das diferenças nos processos educativos. No entanto, com o risco da ação pedagógica, em nome desses pressupostos, cair num particularismo exagerado, num reducionismo pedagógico, num "vale tudo", no qual as possibilidades são tantas quantas forem as diferenças. Diante desse quadro apontarei pressupostos para uma prática pedagógica de EF pautada em pressupostos interculturais, os quais têm na alteridade o argumento relevante do diálogo entre as culturas.

Para tanto, a metodologia consiste em ampla revisão de literatura no campo da antropologia da educação, abarcando autores que discutem a cultura e a diversidade cultural nos processos educativos, estendendo à área da $\mathrm{EF}$, a qual, há pelo menos duas décadas têm debatido este tema no cenário acadêmico, conforme brevemente descrito em linhas anteriores.

\section{CULTURA, DIVERSIDADE CULTURAL E EDUCAÇÃO FÍSICA}

Atualmente, a afirmação da existência de diversas culturas no seio das sociedades tornou-se fato inegável. No entanto, nos alerta Lluch (1998), a percepção desta diversidade cultural é apresentada, freqüentemente, em um sentido restritivo, na direção daqueles "visivelmente" diferentes (imigrantes, índios, ciganos etc.) e associando o fator cultura a traços de origem étnica fato que traduz uma concepção de cultura reduzida, quando não equivocada.

Isso porque a cultura, para além de características de determinado grupo social, representa o modo de viver dos sujeitos, a forma com que estes atribuem significados às suas ações e experiências cotidianas. Representa, conforme Geertz (1989), uma "teia de significados" construída pelos seres humanos e sua análise, operando ao nível das representações dos sujeitos. Ou seja, "moldando" uma lente pela qual se 
enxerga o mundo, não com uma rigidez de fronteira que divide, mas passível de uma flexibilidade que compartilha, sendo essencialmente dinâmica.

[...] a cultura no interior de uma realidade humana é sempre dinâmica, não é fechada ou cristalizada como um patrimônio de raízes fixas e permanentes. A cultura possui fronteiras móveis e em constante expansão. Tampouco é conjugada no singular, já que é plural, marcada por intensas trocas e muitas contradições nas relações entre grupos culturais diversos e mesmo no interior de um mesmo grupo (GUSMÃO, 2003, p. 91)

Partindo desse pressuposto entendo a diversidade cultural não somente reduzida a diferenças de raça, gênero, religião, sexualidade ou ligada a regionalidade, mas sim como um fato que envolve, também, as subjetividades dos sujeitos, a forma em que se relacionam, como se relacionam, com quais visões de mundo, enfim, conforme Gusmão (2003), em todas as dimensões da vida vivida, do nosso cotidiano e até mesmo onde sequer suspeitamos de sua existência.

No entanto, o fator diversidade cultural vem representando ao longo dos últimos anos um problema. Se existe um consenso de que as sociedades são multiculturais, isso não é válido quando a discussão em pauta diz respeito ao "como" tratar a questão.

No que tange à educação escolar, as críticas são contundentes em afirmar a incapacidade da escola no trato com as diferenças. Vários estudos (SACRISTÁN, PERÉZ GÓMEZ, 2000; SACRISTÁN, 1998; SANTOMÉ, 1998) já denunciaram que os conhecimentos das culturas hegemônicas são fortemente enfatizados nas propostas curriculares, fato esse que silencia e/ou oculta outras vozes e outras culturas presentes na sociedade. Segundo Santomé (1998), as culturas silenciadas e/ou negadas são aquelas dos grupos minoritários e/ou marginalizados que, por não disporem de estruturas importantes de poder; acabam por não serem contempladas, quando não estereotipadas e deformadas.

Tais críticas ao sistema escolar têm gerado o repensar dos processos educativos na direção de propostas que contemplem a valorização e o respeito à diversidade cultural dos educandos. Já citei aqui, em linhas anteriores, as abordagens da diversidade e pluralidade cultural, contempladas, respectivamente, na LDB e nos PCN's. Embora sejam passíveis de críticas, não se pode dizer que não representam um avanço em termo de política educacional. No entanto, essas propostas não vêm descoladas de certos riscos e equívocos que, buscando o respeito às diferenças, acabam por relativizar o ensino e reduzir as possibilidades educacionais. 
Valente (2003), ao analisar a LDB no que tange à diversidade cultural, diz que a questão é tratada de maneira genérica e abrangente. A mesma autora, referindo-se à temática da pluralidade cultural nos PCN's, diz que há a percepção de um pragmatismo utópico, pois as críticas feitas à escola permanecem fora de seus muros. Assim, as grandes questões que tangenciam a sociedade, como a desigualdade, a injustiça, os conflitos de classe e de cultura existentes, de alguma maneira seriam neutralizadas no contexto escolar, que se tornaria, desse modo, uma realidade a-histórica (VALENTE, 2003). Para a autora, o pragmatismo utópico desliza para um terreno perigoso quando tenta purificar a escola dos males da sociedade, tendo, nesse momento, um discurso apenas com efeito de retórica e, por isso mesmo, não apresentando alternativa viável ou diferente do que já é conhecido.

Capelo (2003), ao se referir à proposta para Educação de Adultos à luz da teoria de Paulo Freire, afirma que alguns grupos de educação permaneceram restritos ao espaço da realidade circundante, ao gueto cultural do próprio alfabetizando, o que reduziu em muito as possibilidades político-educativas. De acordo com a autora - embasada no próprio Paulo Freire, educar é também, para além de valorizar a cultura do educando, ensinar o sujeito a pensar a si no mundo e, segundo ela, o mundo não pode ser resumido ao pedaço social em que o sujeito se inscreve, é muito mais do que isso.

E a EF? O que ela tem a ver com tudo isso? Partindo do pressuposto de que a mesma é um componente curricular, penso que tem muito a ver. Entendo componente curricular como um elemento da organização escolar que, em sua especificidade de conteúdos, apresenta uma seleção de conhecimentos que, organizados e sistematizados, devem proporcionar ao aluno uma reflexão acerca da dimensão da cultura e que, aliado a outros elementos dessa organização curricular, visa a contribuir com a formação cultural do aluno (SOUZA JÚNIOR, 2001).

E qual seria essa dimensão cultural a ser tratada pela EF? Atualmente, parece consenso falar em cultura corporal ou cultura corporal de movimento, a qual, de acordo com Daólio (2003, p. 123), faz parte de uma cultura humana, constituindo-se "[...] numa área de conhecimentos que estuda e atua sobre um conjunto de práticas ligadas ao corpo e ao movimento criadas pelo homem ao longo de sua história - os jogos, as ginásticas, as lutas, as danças e os esportes”.

A prática da EF é, eminentemente, cultural, devendo estar atenta ao contexto sociocultural do educando e às diferenças apresentadas por eles. No entanto, pode haver aqui o risco da relativização. Por exemplo, um 
professor de EF, atento a essa premissa, ao chegar numa escola e detectar que os alunos gostam e valorizam a prática do futebol pode, pautado no discurso da consideração da realidade dos alunos, acabar "moldando" toda sua ação em torno dessa única prática corporal, tolhendo assim, inúmeras outras possibilidades de acesso ao conhecimento.

Oliveira (2004) elucidou alguns critérios instigantes sobre a seleção de conteúdos feita por professores de educação física em sua prática pedagógica em escolas públicas municipais de Goiânia. Dentre outros, a "aceitação/receptividade dos alunos ao conteúdo" foi um critério citado. Tal justificativa remete a um entendimento possível de que o não imediato ao aluno não traduz um conhecimento significativo a ser abordado. Os professores, ao considerarem este critério, inferem numa aleatoriedade que os impedem enxergar um universo mais amplo de possibilidades.

De acordo com Forquin (1993), o fato de uma criança ter nascido num determinado meio social, em tal bairro da cidade, ao invés de um outro, ela será privada de estudos "abstratos", de conhecimentos históricos ou geográficos não ligados ao circundante e, imediatamente, próximo? Com que direito pode-se impor a certas "categorias" de crianças uma tal discriminação de acesso ao saber? Trata-se aqui de um relativismo exacerbado, como se apenas o local onde os sujeitos vivem bastasse para dizer quem eles são e, dentre outras coisas, o que deve ser abordado em sua escolarização.

Um outro risco possível reside na visão estereotipada de cultura, podendo ser exemplificada pela atuação pedagógica de um professor que, ao efetivar sua prática numa escola que tem negros como maioria dos alunos, enfatizasse a capoeira, o samba e o futebol, entendendo essas manifestações corporais como um patrimônio cultural peculiar aos negros. Garcia (1995), ao discutir formas de superação do preconceito na escola e valorização da diversidade cultural, propõe que se ensine às crianças negras a tocar tambor, a fim de se valorizar uma suposta "cultura negra". Proposições neste sentido não contribuem para o combate ao racismo ou para o adequado tratamento da diversidade cultural, pelo contrário, incorporam, quando não reforçam, os mesmos problemas que se pretende superar, como a crítica ao estereótipo e ao preconceito (VALENTE, 2003).

No entanto, essa é uma realidade muito presente no imaginário dos educadores e da sociedade em geral, que tendem a classificar as pessoas segundo atributos considerados específicos de determinados grupos sociais (CANDAU, 2002). Trata-se de uma concepção “engessada” de cultura, a qual denota a existência 
de fronteiras que separam rigidamente os grupos sociais pelas suas características visivelmente diferentes, o que acaba por escamotear toda uma ação pedagógica e desconsiderar o processo dinâmico da cultura.

Uma outra situação acontece em datas comemorativas, como o Dia do Índio, por exemplo, no qual as ações pedagógicas a serem desenvolvidas nas aulas de EF - pelo menos nas escolas em que tive contato até hoje como aluno e como professor - contemplam práticas corporais que fazem alusão a um ser humano primitivo, habitante das selvas etc. É comum, nessa data, a EF encarregar-se da apresentação de algum tipo de dança ou ritual indígena para a escola. As sugestões para os mesmos estão presentes em livros didáticos especialmente elaborados para essas datas comemorativas que, no caso do Dia do Índio, também incluem algumas lutas e jogos sugeridos para as aulas de EF. A visão contida nesses manuais é aquela romântica, do índio como habitante da selva, em constante contato com a natureza, longe do meio urbano e, por isso mesmo, distante dos problemas sociais (fome, miséria, prostituição, violência etc.) existentes nas cidades. Vale ressaltar aqui que o termo "índio" é uma construção branca, pois, de acordo com Gusmão (2003), os povos indígenas são guarani, avá, terena e outros, mas não são índios. Segundo a autora, chamar todos de "índios" implica desrespeitar a especificidade de cada grupo, alocá-los em um único "padrão cultural", desconsiderando o que são de fato e o que pensam sobre si mesmos como componentes de uma história singular de grupo que tem suas próprias marcas, portadoras de significados, sentidos e visão de mundo únicos.

Esse "modelo" - penso que comum a outras escolas - de se contemplar a diversidade cultural na escolarização dos sujeitos incorre em risco de banalização da cultura dos mesmos, sendo reduzidas, "[...] nos currículos e nas práticas escolares, a conhecimentos triviais que representam as culturas negadas por meio de imagens estereotipadas, turísticas, folclóricas ou comemorativas" (CAPELO, 2003, p. 124).

Fazer isso implica negar, novamente, o pressuposto dinâmico da cultura, estabelecendo fronteiras imóveis entre os grupos sociais que, ao serem enfocados nos currículos dessa forma, apresentam recursos de acentuação das diferenças, e não de reconhecimento. A pluralidade cultural deve ser matéria prima de aprendizagem, mas nunca conteúdo de dias especiais, datas comemorativas ou momentos estanques em sala de aula.

Pensar a EF como prática cultural implica considerar o contexto sociocultural dos alunos e suas diferenças, no entanto, significa também estar atento ao risco dos reducionismos no processo educativo 
dos sujeitos, pois, segundo Valente (2003), a posição relativista acaba refém de uma análise redutora ao voltar sua atenção apenas para o contexto particular no qual a diversidade é produzida.

Endossar a valorização e o respeito às diferenças na educação e na EF parece não causar mais tanta polêmica e resistência. Resta saber como isso pode ser feito sem que haja "escorregões" relativamente exagerados.

\title{
À GUISA DE (IN)CONCLUSÃO: POR UMA EDUCAÇÃO FÍSICA DO DIÁLOGO
}

Ao longo dos últimos anos a $\mathrm{EF}$ vem incorporando às suas ações e concepções pressupostos pedagógicos que caminham na direção de uma prática escolar mais "humana", realçando o contexto sociocultural em detrimento ao tradicional paradigma "tecnicista". Daólio (2003, p. 129), refutando esse pressuposto, afirma que uma prática educativa deve aceitar que

[...] o que torna os alunos iguais é justamente sua capacidade de se expressarem diferentemente”. Ou seja, a diversidade cultural é um fato inegável e que não pode passar despercebido pelos professores, com riscos de uma prática de EF deslocada de sentidos e significados para os alunos.

No entanto, é possível conceber um ensino, não somente de EF, que considere a diversidade cultural sem cair na armadilha do relativismo e/ou do universalismo? Uma prática que, ao mesmo tempo, nem seja igual para todos, nem relativamente diferente, essa última calcada na premissa de que "cada um é um", e se é assim por causa da cultura.

Ao entender, de acordo com Gusmão (2003), que nem a igualdade absoluta, nem a diferença relativa são efetivamente adequadas para compreender e solucionar o problema da diversidade cultural, situo a discussão na alteridade, no sentido de compreender que, para além do reconhecimento (constatação) da diversidade cultural, faz-se necessária a valorização do diálogo, da comunicação entre as culturas.

\begin{abstract}
A alteridade revela-se no fato de que o que eu sou e o outro é não se faz de modo linear e único, porém constitui um jogo de imagens múltiplo e diverso. Saber o que eu sou e o que o outro é depende de quem eu sou, do que acredito que sou, com quem vivo e por quê. Depende também das considerações que o outro tem sobre isso, a respeito de si mesmo, pois é nesse processo que cada um se faz pessoa e sujeito, membro de um grupo, de uma cultura e uma sociedade. Depende também do lugar a partir do qual nós nos olhamos. Trata-se de processos decorrentes de contextos culturais que nos formam e informam, deles resultando nossa compreensão de mundo e nossas práticas frente ao igual e ao diferente (GUSMÃO, 2003, p. 87, grifos da autora).
\end{abstract}

Portanto, se nem todos são como eu sou e isso é fruto do processo dinâmico da cultura, faz-se relevante pensar, no que concerne ao debate educacional, a possibilidade do diálogo entre os "diferentes". Diálogo 
este que, numa aula de EF, por exemplo, cujo tema fosse futebol, estaria preocupado em enfocar as múltiplas possibilidades dessa prática corporal, bem como a multiplicidade de possibilidades que a mesma encerra, partindo do imediato do aluno, mas não se restringindo nele. Isso porque, se a alteridade supõe o outro, com diferentes modos de viver, pensar, brincar, imaginar, sonhar, se emocionar, supondo permanências, reapropriações e mudanças (CAPELO, 2003), é possível imaginar também que essa mesma alteridade, no que diz respeito às práticas corporais, suponha outros "modelos" e "formas" de futebol, voleibol, basquetebol, handebol, ginástica, dança, jogos e lutas que não as hegemônicas, subsidiadas pelo esporte profissional e/ou veiculados pela mídia.

Se a cultura é plural e a alteridade corrobora a existência de diferenças, não faz mais sentido se falar em futebol, mas "futebóis", e assim por diante. Mas não na direção de um laissez faire, de um "vale tudo", o qual a possibilidade do novo advém e se restringe ao imediato do educando, mas sim, no sentido da ampliação do conhecimento, de fazer com que o educando apreenda o conhecimento do "outro", do “diferente" e com ele estabeleça um diálogo profícuo e mútuo, no qual as possibilidades não se encerram a partir de uma única visão. Não nego a possibilidade, por exemplo, do esporte profissional ser abordado nas aulas de EF, mas que este não se constitua em única forma possível de abordagem do esporte e nem seja padrão de aprendizagem, mas sim um conhecimento, como outros tantos, a ser trabalhado nas aulas.

É nesse sentido, do diálogo, do encontro e da comunicação entre as culturas, que Lluch (1998) defende uma educação intercultural, a qual aponta para a promoção de processos educativos que possibilitem uma interação entre as culturas em pé de igualdade e que partam do conhecimento, respeito e valorização mútuos. Segundo o autor, a escola deve perceber na diversidade cultural um elemento enriquecedor. Uma educação que se recusa à “colonização” do outro, mas sim a aprender com esse outro (CAPELO, 2003).

Pensar num pressuposto intercultural para a educação e a educação física implica não somente reconhecer as diferenças e/ou aceitá-las, mas fazer com que elas sejam “[...] a origem de uma dinâmica de criações novas, de inovação, de enriquecimentos recíprocos e não de fechamentos e de obstáculos ao enriquecimento pela troca" (VIEIRA, 1999, p. 68). Pois se não há "rigidez" cultural nas sociedades, não faz sentido que a escola caminhe na contramão desse processo, ignorando os diferentes saberes, valores e interpretações da realidade presentes nesses espaços educativos. 
Dessa forma é que, neste estudo, falo da possibilidade de uma "EF do diálogo" que, calcada em pressupostos interculturais e considerando a alteridade, caminha na direção de compreender as diferentes práticas corporais e os diferentes significados atribuídos a ela como matéria prima de aprendizagem. Uma ação pedagógica que considere essa premissa estará comprometida com a diversificação do processo pedagógico, tanto nos conteúdos a serem abordados como nas diferentes possibilidades de se tratar o mesmo, o que é, minimamente, significativo.

Para uma "EF do diálogo" é necessário também, o entendimento da prática educacional do professor de EF e de seus alunos como, conforme Daolio (2003), criação, recriação e transformação da própria cultura onde estão inseridos, pois, mais do que frutos, os seres humanos são agentes da cultura. Isso implica, a partir do diálogo entre diferenças e diferentes, o caráter de transformação da realidade.

Uma "EF do diálogo" estaria atenta aos riscos do relativismo exagerado que, conforme evidenciado neste estudo, incorre em equívocos pedagógicos no trato com as diferenças e diferentes, o que implica (em) ações e concepções também equivocadas. Pensar numa "EF do diálogo" é, antes de tudo isso, entender que as práticas corporais fazem parte de um patrimônio cultural e que, como tal, devem ser acessadas e apre(e)ndidas pelos sujeitos, inclusive nas suas várias formas de serem pensadas e encenadas nos diversos contextos socioculturais.

Enfim, uma "EF do diálogo" é um diálogo possível da prática educativa com a diversidade cultural que, valendo-se de pressupostos interculturais e da consideração da alteridade, vislumbra e aponta novas relações pedagógicas na escola.

\section{REFERÊNCIAS}

BRASIL: Ministério da Educação, Lei n. 9394/96 de 20 de dezembro de 1996, Estabelece as diretrizes e bases da educação nacional. Diário Oficial, Brasília, 23 dez. 1996, p. 27833 - 27841

BRASIL. Secretaria de Educação Fundamental. Parâmetros curriculares nacionais: introdução aos parâmetros curriculares nacionais. Brasília: MEC/SEF, 1997, v. 1.

CANDAU, V. M. F. Sociedade, cotidiano escolar e cultura (s): uma aproximação. Educação e Sociedade, Campinas: ano 23, n. 79, ago. 2002 
CAPELO, M. R. C. Diversidade sociocultural na escola e a dialética da exclusão/inclusão. In: GUSMÃO, N. M. M. de. (Org.). Diversidade, cultura e educação: olhares cruzados. São Paulo: Biruta, 2003.

DAÓLIO, J. Cultura, educação fisica e futebol. Campinas: Ed. da Unicamp, 2003.

FORQUIN, J. C. Escola e cultura: as bases sociais e epistemológicas do conhecimento escolar. Porto Alegre: Artmed, 1993

GARCIA, R.L. Currículo emancipatório e multiculturalismo: reflexões de viagem. In: SILVA, T.T.; MOREIRA, A.F. (Org.). Territórios contestados: o currículo e os novos mapas políticos e culturais. Petrópolis: Vozes, 1995. p. 114-143.

GEERTZ, C. A interpretação das culturas. Rio de Janeiro: Guanabara Koogan, 1989.

GUSMÃO, N. M. M. de. Os desafios da diversidade na escola. In: GUSMÃO, N. M. M. de. (Org.). Diversidade, cultura e educação: olhares cruzados. São Paulo: Biruta, 2003.

LLUCH, X. Interculturalismo: uma leitura crítica da interculturalidade. Pátio, Porto Alegre, ano 2, n. 6, ago./out. 1998.

MALERBA, J. Entrevista com o professor Boaventura de Souza Santos. Cadernos de Metep, Maringá, 1995, ano 7, n. 6, p. 9-34.

OLIVEIRA, R. C. de. Educação física, ciclos e prática pedagógica: primeiras aproximações. 2004. 87f. Monografia (Especialização em Educação Física Escolar)-Faculdade de Educação Física, Universidade Federal de Goiás, Goiânia, 2004.

SACRISTÁN, J. G.; PÉREZ GOMÉZ, A. I. Compreender e transformar o ensino.4. ed. Porto Alegre: Artmed, 2000.

SACRISTÁN, J. G. O currículo: uma reflexão sobre a prática. 3.ed. Porto Alegre: Artmed, 1998.

SANTOMÉ, J. T. Globalização e interdisciplinaridade: o currículo integrado. Porto Alegre: Artmed, 1998.

SOUZA JÚNIOR, M. O saber e o fazer pedagógicos da educação fisica na cultura escolar: o que é um componente curricular? In: CAPARRÓZ, F. E. (Org.). Educação Física escolar: política, investigação e intervenção. Vitória: Proteoria, 2001. p. 81-92.

VALENTE, A. L. E. F. Conhecimentos antropológicos nos parâmetros curriculares nacionais: para uma discussão sobre a pluralidade cultural. In: GUSMÃO, N. M. M. de. (Org.) Diversidade, cultura e educação: olhares cruzados. São Paulo: Biruta, 2003.

VIEIRA, R. História de vida e identidades. Porto: Afrontamentos, 1999. 


\section{Rogério Cruz de Oliveira}

Faculdade Brasília de São Paulo - FABRASP

\section{Referência do artigo:}

\section{ABNT}

OLIVEIRA, R. C. Educação física e diversidade cultural: um diálogo possível. Conexões, v.5, n. 2, p. 19-30, 2007.

\section{APA}

Oliveira, R. C. (2007). Educação física e diversidade cultural: um diálogo possível. Conexões, 5(2), 19-30.

\section{VANCOUVER}

Oliveira, RC. Educação física e diversidade cultural: um diálogo possível. Conexões, 2007, 5(2): $19-30$. 